\title{
The Perceived Social Support for Job Search Activity Scale (PSS-JSAS): A psychometric evaluation in the context of Ghana
}

\author{
Enoch Teye-Kwadjo ${ }^{1,2}$ (D) \\ Accepted: 26 July 2021 \\ (C) The Author(s), under exclusive licence to Springer Science+Business Media, LLC, part of Springer Nature 2021
}

\begin{abstract}
Lack of social support can have a profound impact on the job search efforts of young adults. The Perceived Social Support for Job Search Activity Scale (PSS-JSAS) was developed to assess the quality of social support a job seeker receives during a job search. Building on this previous work, the present study assessed the PSS-JSAS's factor structure, construct validity, reliability, and measurement invariance in the context of Ghana. Data for the present analysis were provided by 429 recent university graduates. The sample was randomly split into two subsamples for exploratory factor analysis (EFA; $n=223)$ and confirmatory factor analysis $(\mathrm{CFA} ; n=206)$. EFA and parallel analysis with the first subsample suggested a single factor structure, comprising 6 items out of the original 8 items. In CFA with the second subsample, the construct validity of the single factor structure was found to be optimal. Multi-group CFA with the second subsample showed that the single factor structure was invariant across gender. Further, reliability analysis on the total sample and the subsamples demonstrated good internal consistency reliability for the 6 items. The validity evidence obtained in this study suggests that the PSS-JSAS has good psychometric properties and is thus suitable for assessing social support for job search efforts of university graduates.
\end{abstract}

Keywords Social support · Job search $\cdot$ Confirmatory factor analysis $\cdot$ Measurement invariance $\cdot$ Psychometrics

\section{Introduction}

Lack of social support can have a profound impact on the job search efforts of young adults. Numerous studies have shown that unemployment adversely affects the psychological and physical wellbeing of people (McKee-Ryan et al., 2005; Mousteri et al., 2018; Paul \& Moser, 2009) and is particularly devastating for unemployed young adults (Mokona et al., 2020; Thern et al., 2017). Most of the job search literature has focused on job search behavior of the individual (see Hoye et al., 2015; Vansteenkiste et al., 2016). However, much less research has been aimed at understanding the social support system that is available to the young adult job seeker. Therefore, we know very little about how young adult job seekers cope with disappointment arising out of a job search. Social support has long been established to buffer the effects

Enoch Teye-Kwadjo

etk@sun.ac.za; eteye-kwadjo@ug.edu.gh

1 Department of Industrial Psychology, Stellenbosch University, Private Bag X1, Matieland 7602, South Africa

2 Department of Psychology, University of Ghana, P. O. BOX LG84Legon Accra, Ghana of negative life events on a person's mental health and physical well-being (Affram et al., 2019; Feeney \& Collins, 2015; Zimet et al., 1988). Thus, social support is widely recognized as a crucial coping resource in stressful situations, in general, and during the period of a person's inability to find a job, in particular (Holmstrom et al., 2015; Kanfer et al., 2001; Vinokur \& van Ryn, 1993).

For example, in two studies, one among new-entrant job seekers and the other among unemployed and underemployed workers, Holmstrom et al. (2015) examined the relationship between the receipt of esteem social support, self-efficacy, and job-search behavior. They described esteem support as supportive messages intended to enhance a recipient's job-search self-esteem. They argued that esteem social support might enhance a job seeker's self-esteem. Results showed that esteem social support related positively to job-search self-efficacy and job-search behavior, with job-search self-efficacy mediating the esteem social support-job-search behavior relationship in both studies. The authors observed that esteem social support appeared more salient for job search efforts in the new-entrant job seekers sample than it was in the unemployed and underemployed sample. Holmstrom et al.'s (2015) findings highlight the importance of social support for new job seekers such as new university graduates. 
Available reports in Ghana indicate that only $10 \%$ of graduates are employed one year after leaving university (Ghana News Agency, 2017; Institute of Statistical, Social, and Economic Research [ISSER], 2017; Yeboah, 2019). See also Dadzie et al. (2020), World Bank (2020), Ghana Statistical Service (2016), and Adogla-Bessa (2020) for more information on youth unemployment in Ghana. Ghanaian university graduates may experience frustration, despair, and psychological distress, following their inability to find jobs. The graduate unemployment problem may worsen because of the impact of the COVID-19 pandemic on businesses and organizations in Ghana (Ghana Statistical Service, 2020). Consequently, graduate job seekers would require more social support for job search efforts during and after COVID-19 than they did at any time in Ghana's recent employment history.

Ghanaian cultural context emphasizes connectedness, embeddedness, and interdependence between community members (Hofstede et al., 2010; Marbell \& Grolnick, 2013; Schwartz, 2006). It is a cultural context that values relationships and the achievement of group goals (Salm \& Falola, 2002). Being a context with a tight culture (see The Inglehart-Welzel World Cultural Map, 2020), group norms influence the behavior, feelings, and thoughts of people in Ghana (Assimeng, 2007; Nukunya, 2016). Because people from tight cultures tend to demonstrate less competitive behavior and view the environment as stable but themselves as changeable (see Markus \& Kitayama, 1991; Markus \& Kitayama, 2010; Uz, 2015), Ghanaian graduate job seekers would require support from family, friends, and significant others to persevere in the job search process, which is known to demand individual expression, high self-esteem, and personal responsibility. Social support is thus an important coping resource in Ghana (see Affram et al., 2019; Gyasi et al., 2020).

Lack of social support for a job search may discourage graduate job seekers from further job search activities. The protective effects of social support can help graduate job seekers deal with stressors associated with job search efforts. Therefore, evaluating social support for job search efforts in this population is very important and warranted. Yet, to our knowledge, no research has investigated how social support influences the job search efforts of graduates in Ghana. One way to achieve this goal would be to use a job-search-specific social support scale that is valid and reliable. The purpose of this study, therefore, was to investigate the utility of the Perceived Social Support for Job Search Activity Scale (PSS-JSAS) in recent university graduates in Ghana. Next, we offer a description of the PSS-JSAS.

Rife and Belcher (1993) developed the 8-item PSS-JSAS in response to the need to have a domain-specific social support scale that is devoted to job search efforts, aside from the various scales available in the literature for assessing global social support such as the Multidimensional Scale of Perceived Social Support (MSPSS; Zimet et al., 1988). It is evident from the literature that job search-specific social support has been somewhat overlooked, save the pioneering work of Rife and Belcher (1993). They established the validity of the PSS-JSAS through expert reviews. However, the authors did not provide information on the factor structure of the scale. Thus, there is a need to examine the scale's factor structure. A few writers have long noted the importance of assessing domain-specific social support (see Davis et al., 1998; Jung, 1990; Sarason et al., 1994). They argued that a domain-specific measure of social support (e.g. social support for job search activities) may yield a greater understanding of aspects of a person's social functioning than measures of general social support.

It is worth noting that the relevance of the PSS-JSAS is hinged on social support theory. Social support theorists have consistently shown that social support can protect a person against stressors as well as strengthen a person in the absence of stressors (Lakey \& Cohen, 2000; Sarason \& Sarason, 2009; Uchino, 2006). Given that the job search process is highly uncertain and can be frustrating, especially for young adults, having access to social support before, during, and after a job search effort may not only promote self-esteem for further job search efforts, but also it may prevent feelings of learned helplessness and anxiety. Learned helplessness (see Maier \& Seligman, 2016; Peterson, 2010; Smallheer, \& Vollman, \& Dietrich, M. S., 2018) is thought to arise when people (e.g. job seekers) feel that they have little control over achieving success in a particular endeavor (e.g. failing to secure a job after repeated job search attempts).

Further, the measurement invariance of the PSS-JSAS remains unknown because Rife and Belcher (1993) did not examine it. Previous work has shown that there are gender differences in perceived social support (Matud et al., 2003) and the provision of job search help (Zhou, 2019). Therefore, it would be useful to investigate the measurement invariance of the PSS-JSAS across gender to provide opportunities for meaningful comparisons of means and relationships between the latent construct across groups. Measurement invariance evaluates whether the same latent construct is measured across groups or time on the same metric (Pendergast et al., 2017; Putnick \& Bornstein, 2016). If measurement invariance is established, it shows that the construct has the same structure or meaning to both groups, and thus fulfills the pre-requisite for comparing the groups (Davidov et al., 2014). Taken together, the goal of the present study was to examine the factor structure and construct validity of the domain-specific PSS-JSAS in recent university graduates using robust statistical techniques such as confirmatory factor analysis. Another aim was to establish the measurement invariance of the PSS-JSAS across gender. 


\section{Method}

\section{Participants}

A total of 429 recent university graduates in Ghana provided data for this study.

The mean age of the sample was $24.1(S D=2.8)$. The sample comprised 215 males and 214 females. Approximately, 58\% indicated that they were living with family, whereas $32.6 \%$ were living alone, and $9.1 \%$ were living with friends. This work is part of the School-to-Work Transition (SWoT) study aimed at validating selected job search and career interest measures in Ghana. Inclusion criteria involved being a recent university graduate, being unemployed, and making the school-to-work transition under the Ghana National Service Scheme (NSS). NSS personnel in Ghana are graduates from accredited tertiary institutions who are required by law to serve the government and people of Ghana in public or private organizations under a one-year mandatory service scheme (for more information on Ghana's NSS, see the NSS's website at https://nss.gov.gh). Convenience sampling techniques were used to recruit participants for the study. The convenience sampling involved approaching and recruiting service personnel at their various work places. They were not recruited using the database of the NSS. Four hundred and eighty questionnaires were distributed, and 429 completed questionnaires were returned. The confidentiality of participation and the anonymity of responses were guaranteed. Participants completed the questionnaire in the English language. The study was approved by the Institutional Review Board of the University of Ghana (Ref\#: ECH116/19-20).

\section{Measure}

Social support for a job search was assessed with the Perceived Social Support for Job Search Activity Scale (PSS-JSAS) developed by Rife and Belcher (1993). The PSS-JSAS is an 8-item self-report measure (see Table 1) that assesses the quality of social support a job seeker receives during their job search efforts. The PSS-JSAS was developed in the United States using unemployed participants. Rife and Belcher (1993) reported Cronbach's alpha of .84 for the 8 items. All of the items are rated on a 5-point Likert scale from 1 (strongly disagree) to 5 (strongly agree). Two items are negatively keyed (item\#3 and item\#6). Respondents also provided data on gender, age (years), and living status (i.e. living with family, with friends, or alone).

\section{Statistical Analysis}

\section{Exploratory Factor Analysis}

First, the two negatively keyed items on the PSS-JSAS were reverse-scored. Next, the data were checked for univariate and multivariate normality, missing data, and floor or ceiling effects. The data were normally distributed, with no missing data or floor/ceiling effects. Then, descriptive statistics were calculated for the demographic variables and the scale items. To evaluate the factor structure of the PSS-JSAS, the split sample procedure for scale validation was followed (see Coelho et al., 2018; Lam et al., 2020; Liss et al., 2013; Ng, 2013). Specifically, the sample size of 429 was randomly divided into two subsamples using the random case selection function in SPSS. Exploratory factor analysis (EFA) was conducted

Table 1 Descriptive Statistics of the Perceived Social Support for Job Search Activity Scale (PSS-JSAS ${ }^{\dagger}$ )

\begin{tabular}{|c|c|c|c|c|c|}
\hline Item \# & Item description & $M$ & $S D$ & Skew & Kurtosis \\
\hline 1. & I feel that I am receiving a high level of support for my job search efforts. & 2.62 & 1.15 & 0.22 & -0.85 \\
\hline 2. & $\begin{array}{l}\text { When I am turned down for a job interview, I receive positive encouragement } \\
\text { for continuing my job search efforts. }\end{array}$ & 2.84 & 1.08 & -0.16 & -0.75 \\
\hline 3. & I feel all alone in dealing with the frustrations of searching for a job (R). & 3.01 & 1.05 & 0.10 & -0.53 \\
\hline 4. & Others encourage me to continue searching for a job even when I feel down. & 3.07 & 1.00 & -0.19 & -0.45 \\
\hline 5. & I feel that others understand why I want to continue working. & 3.02 & 1.07 & -0.04 & -0.63 \\
\hline 6. & No one really understands how hard it is to find a job these days (R). & 3.00 & 1.17 & -0.00 & -0.77 \\
\hline 7. & If I feel like quitting my search for a job, others encourage me to keep contacting employers. & 2.95 & 1.09 & 0.02 & -0.57 \\
\hline 8. & When it comes to searching for a job, I have others supporting me. & 3.02 & 1.09 & -0.08 & -0.66 \\
\hline
\end{tabular}

Note. Rating scale: 1 (strongly disagree), 2 (disagree), 3 (neither disagree nor agree), 4 (agree), 5 (strongly agree)

$M=$ mean, $S D=$ standard deviation. $\mathrm{R}=$ reverse coded item

$\dagger=$ All of the items on the PSS-JSAS are available in Rife and Belcher (1993) 
on subsample $1(n=223)$ and confirmatory factor analysis (CFA) and measurement invariance were performed on sub-sample $2(n=206)$. With 8 items on the PSS-JSAS, subsample $1(n=223)$ exceeded the 20:1 participant-to-item ratio recommended by Osborne (2014) and by Carpenter (2018) for determining adequate sample sizes in EFA. Note that adequate sample sizes in EFA guarantee stable factors and generalizable results.

Before conducting the EFA and as part of data screening, we performed a bivariate correlation analysis on the 8 items of the PSS-JSAS. The correlation matrix showed that the two negatively keyed items (i.e. items \#3 and \#6) correlated negatively, nonsignificantly with the rest of the items, despite reverse scoring. The two items, however, correlated moderately between themselves $(r=.18, p<.01)$. To get a clearer picture of their psychometric functioning, we reversed the two items to their original scoring and repeated the bivariate correlation analysis. They correlated negatively with the rest of the items again. It was surmised that respondents may not have noticed that the two items were negatively keyed, a potential case of acquiescent response bias. Consequently, we removed item\#3 and item\#6 from subsequent analysis on the scale. Next, we performed EFA using the remaining 6 items of the scale. Following Carpenter's (2018) recommendations, we used Maximum Likelihood (ML) and Direct Oblimin for factor extraction and factor rotation, respectively. Then, we determined the number of factors to extract using parallel analysis (PA). We used Field's (2018) loading $>.40$ criterion to determine minimum factor loading (see Table 2).

\section{Confirmatory Factor Analysis and Measurement Invariance}

We conducted CFA on subsample $2(n=206)$ to verify the structural validity of the factor solution obtained in the EFA procedure. The ML estimator was used. Model fit was evaluated with the comparative fit index (CFI $\geq .95)$, root-mean-square error of approximation (RMSEA $\leq .07$ ) with $90 \%$ confidence interval, and the standardized root-mean-square residual (SRMR $\leq .08$; West et al., 2012). We calculated internal consistency reliability for the 6-item PSS-JSAS for the total sample and each subsample using both Cronbach's alpha and McDonald's omega.

Further, we tested measurement invariance across gender (males vs. females) using multi-group confirmatory factor analysis (MG-CFA) to gather more validity evidence about the scale's psychometric functioning. Four increasingly more restrictive measurement invariance models were tested across gender. They included (1) configural (equal form model across groups), (2) metric (factor loadings constrained to equality across groups), (3) scalar (item intercepts constrained to equality across groups), and (4) strict (residual variances constrained to equality across groups). We evaluated differences in nested models using change in $\mathrm{CFI}(\Delta \mathrm{CFI} \leq-.01)$ in conjunction with changes in RMSEA $(\triangle \mathrm{RMSEA} \leq .02)$ and SRMR $(\triangle$ SRMR $\leq .03)$ as recommended by Cheung and Rensvold (2002) and by Chen (2007), respectively. In other words, when two sequentially nested models are compared, a change in the magnitude of CFI less than or equal to -.01, or RMSEA less than or equal to .02 , or of SRMR less than or equal to .03 would indicate that the more restrictive model should be accepted. In this study, the EFA was calculated in SPSS (v25). PA was conducted in Monte Carlo PCA for Parallel Analysis. The CFA and MG-CFA were undertaken in Mplus (v7.0).

Table 2 Factor Loadings of the Perceived Social Support for Job Search Activity Scale (PSS-JSAS ${ }^{\dagger}$ ) from Exploratory Factor Analysis in Subsample 1 $(n=223)$

\begin{tabular}{|c|c|c|c|c|c|}
\hline Item \# & Item description & Range & $h^{2}$ & $\begin{array}{l}\text { Item-total } \\
\text { correlation }\end{array}$ & $\begin{array}{l}\text { Factor } \\
\text { loading }\end{array}$ \\
\hline 4. & Others encourage me to continue searching for a job even when I feel down. & $1-5$ & .56 & .64 & .75 \\
\hline 7. & If I feel like quitting my search for a job, others encourage me to keep contacting employers. & $1-5$ & .55 & .65 & .74 \\
\hline 5. & I feel that others understand why I want to continue working. & $1-5$ & .43 & .55 & .66 \\
\hline 2. & $\begin{array}{l}\text { When I am turned down for a job interview, I receive positive encouragement } \\
\text { for continuing my job search efforts. }\end{array}$ & $1-5$ & .41 & .59 & .64 \\
\hline 8. & When it comes to searching for a job, I have others supporting me. & $1-5$ & .32 & .48 & .56 \\
\hline 1. & I feel that I am receiving a high level of support for my job search efforts. & $1-5$ & .24 & .45 & .49 \\
\hline \multicolumn{5}{|c|}{ Eigenvalue } & 3.05 \\
\hline \multicolumn{5}{|c|}{ Total \% of variance explained } & 50.8 \\
\hline \multicolumn{5}{|c|}{ Cronbach's alpha } & .80 \\
\hline
\end{tabular}

Note. Extraction method: maximum likelihood; rotation method: oblimin; number of factors to extract: parallel analysis

$h^{2}=$ extraction communalities

$\dagger=$ All of the items on the PSS-JSAS are available in Rife and Belcher (1993) 


\section{Results}

\section{Exploratory Factor Analysis}

Kaiser-Meyer-Olkin (KMO) measure of sample adequacy was .812 and Bartlett's test of sphericity was, $\chi^{2}(15)=$ $391.42, p<.001$, indicating that the data in subsample 1 were factorable and appropriate for conducting the EFA. The Determinant of the correlation matrix was .168 , which exceeded the minimum recommended value of 0.0001 . The Determinant (.168) indicates the absence of multicollinearity and singularity in our data. Parallel analysis with 1000 replications in the Monte Carlo simulation confirmed that one-factor solution was optimal. All items loaded $(r>.40)$ on the factor (see Table 2). The factor explained a total variance of $50.8 \%$. Corrected item-total correlation values ranged from, $r=.45$ to $r=.65$.

\section{Confirmatory Factor Analysis}

The CFA on subsample $2(n=206)$ revealed that the single factor solution provided a good fit to the data, $\chi^{2}(9)=21.95$, $p<.01, \mathrm{CFI}=.95, \mathrm{RMSEA}=.08,90 \%$ CI $[.04, .13]$, SRMR $=.04$. All of the factor loadings were significant, $p<.001$. Factor loadings of the latent construct ranged between .50 and .70 (see Fig. 1).

\section{Measurement Invariance}

Results from the invariance testing showed that configural, metric, scalar, and strict invariance was obtained across gender, as evidenced by the good model fit and acceptable changes in CFI, RMSEA, and SRMR (see Table 3). For example, a comparison of the configural model with the metric model showed that the change in magnitude of the CFI $(\triangle \mathrm{CFI})$, RMSEA ( $\triangle$ RMSEA), and the SRMR ( $\triangle$ SRMR) was less than or equal to the cut-off criteria of $-.01, .02$, and .03 for CFI, RMSEA, and SRMR, respectively. The results demonstrated that the factor loadings between the two groups (males vs. females) were equivalent.

\section{Reliability}

Score reliability was calculated with McDonald's omega $(\omega)$ and Cronbach's alpha $(\alpha)$ separately for subsample 1 and subsample 2, as well as the total sample. Subsample $1(n=$ 223) had high internal consistency reliability estimates $(\omega$ $\left.=.80, \mathrm{CI}_{95 \%}[.76, .84] ; \alpha=.80, \mathrm{CI}_{95 \%}[.76,84]\right)$. Subsample $2(n=206)$ had acceptable reliability estimates $(\omega=.78$, $\left.\mathrm{CI}_{95 \%}[.73, .81] ; \alpha=.78, \mathrm{CI}_{95 \%}[.72,82]\right)$. In addition, the total sample $(N=429)$ demonstrated good internal consistency reliability ( $\left.\omega=.79, \mathrm{CI}_{95 \%}[.76, .82] ; \alpha=.79, \mathrm{CI}_{95 \%}[.76,82]\right)$.

\section{Discussion}

The present study aimed to provide sound psychometric evidence for the use of the Perceived Social Support for Job Search Activity Scale (PSS-JSAS) among graduate job seekers in Ghana. Overall, the results demonstrated a stable single factor structure with good reliability and construct validity for the 6-item PSS-JSAS. The results suggest that the PSS-JSAS is a useful measure for assessing social support for a job search effort of young adult job seekers in Ghana.
Fig. 1 Confirmatory Factor Analysis Model of the Perceived Social Support for Job Search Activity Scale (PSS-JSAS) in Subsample $2(n=206)$. Note. CFI = comparative fit index, RMSEA $=$ root mean square error of approximation, $\mathrm{SRMR}=$ standardised root mean square residual. $\mathrm{CI}_{90 \%}=90 \%$ confidence interval. Standardised factor loadings, residual variances, and standard errors are reported. All coefficients are significant $(p<.001)$.

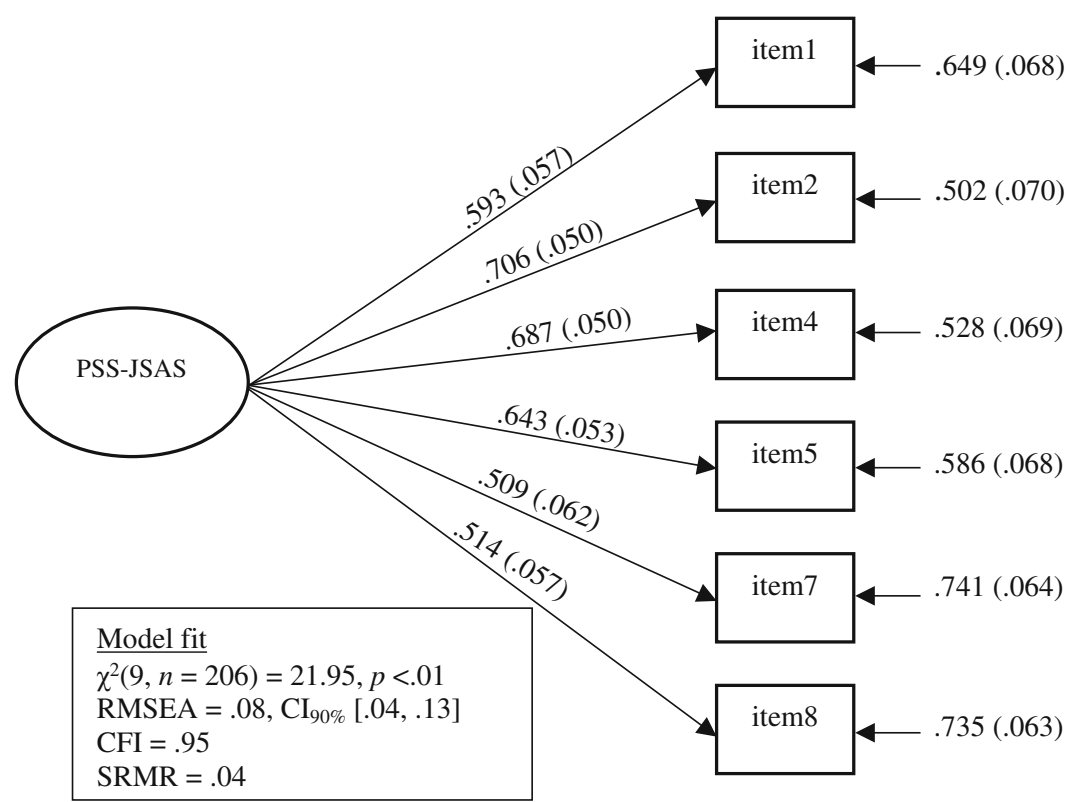


Table 3 Fit Statistics for the Multi-Group Invariance Testing Across Gender in Subsample $2(n=206)$

\begin{tabular}{|c|c|c|c|c|c|c|c|c|}
\hline Model & $x^{2}$ & $d f$ & CFI & SRMR & $\mathrm{RMSEA}\left[\mathrm{CI}_{90 \%}\right]$ & $\Delta \mathrm{CFI}$ & $\Delta \mathrm{SRMR}$ & $\triangle \mathrm{RMSEA}$ \\
\hline 0 . Initial model & $21.95^{* *}$ & 9 & .95 & .04 & $.08[.04, .13]$ & - & - & - \\
\hline 1. Configural invariance & $38.87^{* *}$ & 18 & .93 & .05 & $.11[.06, .15]$ & - & - & - \\
\hline 2. Metric invariance & $44.35^{* *}$ & 23 & .93 & .07 & $.10[.05, .14]$ & -.00 & .02 & -.01 \\
\hline 3. Scalar invariance & $51.41^{* *}$ & 28 & .92 & .08 & $.09[.05, .13]$ & -.01 & .01 & -.01 \\
\hline 4. Strict invariance & $58.85^{* *}$ & 34 & .91 & .11 & $.08[.05, .12]$ & -.01 & .03 & -.01 \\
\hline
\end{tabular}

Note. Male $=110$, female $=96$;

$\mathrm{CFI}=$ comparative fit index, RMSEA = root mean square error of approximation, $\mathrm{SRMR}=$ standardised root mean square residual,

$\mathrm{CI}=$ confidence interval, $\Delta=$ change in the statistic

${ }^{* * *} P<.01$

Although it is well known that the theoretical reason for having mixed-keyed items in a measure is to reduce response bias such as acquiescent responding, some researchers and practitioners have questioned this strategy (see DiStefano \& Motl, 2006; Ebesutani et al., 2012; McLarnon et al., 2016; Molina et al., 2014), arguing that it constitutes a threat to the validity and reliability of most measures. For example, Roszkowski and Soven (2010) demonstrated that including two negatively keyed items in the middle of several positively keyed items in a measure gives rise to ambiguity instead, and does very little to control for acquiescent bias. In addition, van Sonderen et al. (2013) concluded that adding a few negatively keyed items to a measure of many positive items misleads survey respondents and rarely prevents response bias.

As an example, in the present study data screening revealed that two negatively keyed items on the PSS-JSAS appeared problematic because they correlated negatively but weakly with the rest of the items, despite that they had been reversed scored. Further examination of the two items showed that they related positively, but moderately to each other. Item analysis indicated that the poor performance of the two items may have arisen from wording effects. In other words, respondents did not seem to have recognized that the two items were worded in the negative direction, unlike the rest of the items. This reflects the acquiescent bias that arose from the ambiguity of the response options. Based on this literature, we suggest that future work on the PSS-JSAS should avoid mixing both positively and negatively keyed items as this practice could pose threats to the validity and reliability of the scale, as evidenced in the present study.

Moreover, the results of the CFA suggest that the measurement model was adequate. That is, the CFA found that the single latent factor and the 6 observed continuous indicators demonstrated a good fit to the sample data. All factor loadings were statistically significant. Note that prior structural equation modeling seminal work suggested that a CFI value of .95 or higher demonstrate good fit, whereas RMSEA value of .07 or lower, and SRMR value of .08 or lower are indicative of good model fit (see Browne \& Cudeck, 1992; Hu \& Bentler, 1999). For example, except for $\chi^{2}$ which was significant (and which was expected due to the large sample size), fit indices for the CFI, RMSEA, and SRMR satisfied the minimum threshold of acceptable fit. We did not undertake any model modifications. Our CFA results demonstrated that our observed variables were generated by the latent construct and that the regression paths (i.e. factor loadings) from the latent construct to the observed variables were statistically significant, indicating that our CFA model described our sample data adequately. This result implies that the CFA has confirmed the postulated relations between the observed indicators and the underlying factor (i.e. the specified single factor model) to be psychometrically sound for use in research.

Regarding the results of the multi-group CFA, the invariance testing for the specified single factor model revealed that configural, metric, scalar, and strict invariance across males and females was achieved. For example, configural invariance was estimated simultaneously across gender using equal forms of the model (i.e. no constraints on parameters). The results demonstrated that the same factor structure was obtained in both gender groups. The establishment of configural invariance provided the basis for the subsequent invariance analysis (i.e. metric invariance). Metric invariance is considered crucial for demonstrating construct validity because of its ability to determine how well the indicators relate to the factor across groups (Meredith \& Teresi, 2006; Vandenberg, 2002; Vandenberg \& Lance, 2000). In this study, the metric model showed that there is equality of factor loading across the two groups. In other words, the manifest variables did not fail to measure the latent variable in the same way across men and women. Subsequent invariance testing found scalar and strict invariance to be present in the data, indicating the establishment of full measurement invariance across gender. The invariance results obtained in this study indicate that meaningful comparisons of the trait across gender 
can be made. Furthermore, reliability analysis using both McDonald's omega and Cronbach's alpha with the total sample as well as the subsamples found good reliability estimates for the 6-item PSS-JSAS. Taken together, the results obtained in the present study provided preliminary evidence for the construct validity and reliability of the 6-item PSS-JSAS.

The results have important implications for research and theory building. Practically, the PSS-JSAS is a psychometrically sound measure and may be used to conduct both basic and applied research with new job seekers, especially graduate job seekers. For example, career counselors and employment advisors may use the PSS-JSAS as an assessment tool among job seekers to assess how they search for jobs and to help identify the form of social support available to new-entrant job seekers as well as the unemployed and underemployed. Theoretically, the results extend the application of social support theory to the job search domain. They also extend the concept of social support for job search activities to a new cultural context, Ghana. The satisfactory performance of the items on the PSS-JSAS in the Ghanaian sample highlights the salience of social support for people and by extension the salience of group solidarity in this cultural context. The salience of social support for job search activities for the present sample is consistent with Ghana's cultural value orientations which emphasize identification with the group, respect for social relationships, and a striving towards the achievement of shared goals. In other words, the conceptual definition and operationalization of the social support construct seem meaningful to the present Ghanaian sample, given their cultural value orientations. Taken together, our study provides a point of reference for further work on social support theory in the context of Ghana.

\section{Limitations}

A potential limitation of this study is the use of a convenience sample. Convenience samples are known to limit the generalizability of scientific investigations. In addition, the relatively small sample size used is another limitation, although it was found to be adequate for the current study. Larger sample size may have provided sufficient power to produce more precise parameter estimates. Future research on the PSS-JSAS should consider using large, random samples. Another limitation to note is that the present study examined only the internal structure of the PSS-JSAS. Future research on the scale may extend our results by evaluating the PSS-JSAS' construct validity within its nomological network of theoretically related constructs. This research may provide further validity evidence of the PSS-JSAS as a theoretically and statistically sound measure of social support for job search activities.

\section{Conclusion}

In this study, we investigated the psychometric properties of the PSS-JSAS. The study found strong validity evidence for the use of the 6-item PSS-JSAS for assessing social support for job search activities in the context of Ghana. In addition, multi-group invariance analysis revealed that scores on the latent variable can be meaningfully compared across males and females, having established that the underlying measurement model was equivalent across the two groups. That is to say, the relationships between the latent variable scores and the continuous observed indicators in the present study do not depend on gender group membership. Thus, it would seem that perceived social support for job search activities is conceptualized similarly across males and females, as demonstrated by the latent factor in the multi-group CFA. Despite the sound psychometric properties reported for the PSS-JSAS in the present sample, its practical utility warrants further testing in various job seeker subpopulations in the context of Ghana.

Acknowledgements This study was generously supported by a postdoctoral fellowship award from the Department of Industrial Psychology, Stellenbosch University, to the author.

Availability of Data and Material The data on which the article reports are available from the corresponding author on reasonable written request.

Funding There is no funding to report for this study.

\section{Declarations}

Conflict of Interest The author declares that they have no conflicts of interest to report.

Ethics Approval The study protocol was approved by the Institutional Review Board of the University of Ghana (Ref\#: ECH116/19-20). All procedures performed in the study were by the ethical standards of the Ethics Committee for the Humanities (ECH) of the University of Ghana and with the 1964 Helsinki Declaration and its later amendments or comparable ethical standards.

Consent to Participate Informed consent was obtained from all of the participants of the study.

Consent for Publication Consent for publication was obtained from all of the participants of the study.

\section{References}

Adogla-Bessa, D. (2020). Unemployment, education priority concerns for Ghana's youth - Afrobarometer report. Retrieved from https:// citinewsroom.com/2020/08/unemployment-education-priorityconcerns-for-ghanas-youth-afrobarometer-report/, accessed on 16/ 08/2020. 
Affram, A. A., Teye-Kwadjo, E., \& Gyasi-Gyamerah, A. A. (2019). Influence of social stigma on subjective well-being of persons with albinism in Ghana. Journal of Community and Applied Social Psychology, 29, 323-335. https://doi.org/10.1002/casp.2403

Assimeng, M. (2007). Social structure of Ghana: A study in persistence and change. Ghana Publishing Corporation.

Browne, M. W., \& Cudeck, R. (1992). Alternative ways of assessing model fit. Sociological Methods \& Research, 21(2), 230-258. https://doi.org/10.1177/0049124192021002005

Carpenter, S. (2018). Ten steps in scale development and reporting: A guide for researchers. Communication Methods and Measures, 12(1), 25-44. https://doi.org/10.1080/19312458.2017.1396583

Chen, F. F. (2007). Sensitivity of goodness of fit indexes to lack of measurement invariance. Structural Equation Modeling, 14, 464 504. https://doi.org/10.1080/10705510701301834

Cheung, G. W., \& Rensvold, R. B. (2002). Evaluating goodness-of-fit indexes for testing measurement invariance. Structural Equation Modeling, 9, 233-255. https://doi.org/10.1207/ S15328007SEM0902_5

Coelho, G. L. H., Vilar, R., Hanel, P. H. P., Monteirod, R. P., Ribeiro, M. G. C., \& Gouveia, V. V. (2018). Optimism scale: Evidence of psychometric validity in two countries and correlations with personality. Personality and Individual Differences, 134, 245-251. https:// doi.org/10.1016/j.paid.2018.06.030

Dadzie, C. E., Fumey, M., \& Namara, S. (2020). Youth employment programs in Ghana: Options for effective policymaking and implementation. https://openknowledge.worldbank.org/bitstream/ handle/10986/34349/9781464815799.pdf? sequence $=$ 2\&isAllowed=y. Accessed 23 Jan 2021

Davidov, E., Meuleman, B., Cieciuch, J., Schmidt, P., \& Billiet, J. (2014). Measurement equivalence in cross-national research. Annual Review of Sociology, 40, 55-75. https://doi.org/10.1146/annurevsoc-071913-043137

Davis, M. H., Morris, M. M., \& Kraus, L. A. (1998). Relationship-specific and global perceptions of social support: Associations with well-being and attachment. Journal of Personality and Social Psychology, 74(2), 468-481. https://doi.org/10.1037/0022-3514.74.2.468

DiStefano, C., \& Motl, R. W. (2006). Further investigating method effects associated with negatively worded items on self-report surveys. Structural Equation Modeling: A Multidisciplinary Journal, 13(3), 440-464. https://doi.org/10.1207/s15328007sem1303_6

Ebesutani, C., Drescher, C. F., Reise, S. P., Heiden, L., Hight, T. L., Damon, J. D., \& Young, J. (2012). The loneliness questionnaireshort version: An evaluation of reverse-worded and non-reverseworded items via item response theory. Journal of Personality Assessment, 94(4), 427-437. https://doi.org/10.1080/00223891. 2012.662188

Feeney, B. C., \& Collins, N. L. (2015). A new look at social support: A theoretical perspective on thriving through relationships. Personality and Social Psychology Review, 19(2), 113-147. https://doi.org/10.1177/1088868314544222

Field, A. (2018). Discovering statistics using SPSS. (5th ed.). SAGE publications. Gender \& Society, 33(5), 746-771. https://doi.org/10. $1177 / 0891243219854436$

Ghana News Agency (2017). Only 10 percent of graduates find jobs after first year - ISSER Research. Retrieved from https://www. myjoyonline.com/news/2017/june-3rd/only-10-percent-of-graduatesfind-jobs-after-first-year-isser-research.php, accessed on 18/07/2020.

Ghana Statistical Service (2016). 2015 Labor force report. Retrieved from https://statsghana.gov.gh/gssmain/fileUpload/Demography/ LFS\%20REPORT_fianl_21-3-17.pdf, accessed on 16/08/2020.

Ghana Statistical Service. (2020). How COVID-19 is affecting firms in Ghana: Results from the business tracker survey. Retrieved from https://statsghana.gov.gh/gssmain/fileUpload/pressrelease/Business\% 20Tracker\%20Brief\%20Report GSS web.pdf, accessed on 16/08/ 2020.
Gyasi, R. M., Phillips, D. R., \& Amoah, P. A. (2020). Multidimensional social support and health services utilization among noninstitutionalized older persons in Ghana. Journal of Aging and Health, 32(34), 227-239. https://doi.org/10.1177/0898264318816217

Hofstede, G., Hofstede, G. J., \& Minkov, M. (2010). Cultures and organizations: Software for the mind ( $3 r d$ ed.). McGraw-Hill.

Holmstrom, A. J., Russell, J. C., \& Clare, D. D. (2015). Assessing the role of job-search self-efficacy in the relationship between esteem support and job-search behavior among two populations of job seekers. Communication Studies, 66(3), 277-300. https://doi.org/10.1080/ 10510974.2014.991043

Hoye, G. V., Saks, A. M., Lievens, F., \& Weijters, B. (2015). Development and test of an integrative model of job search behavior. European Journal of Work and Organizational Psychology, 24(4), 544-559. https://doi.org/10.1080/1359432X.2014.964214

$\mathrm{Hu}$, L.-t., \& Bentler, P. M. (1999). Cutoff criteria for fit indexes in covariance structure analysis: Conventional criteria versus new alternatives. Structural Equation Modeling, 6(1), 1-55. https://doi.org/ 10.1080/10705519909540118

Institute of Statistical, Social, and Economic Research [ISSER] (2017). Only 10\% of graduates find jobs after the first year - ISSER. Retrieved from https://isser.edu.gh/index.php/research-impact/104only-10-of-graduates-find-jobs-after-the-first-year-isser, accessed on $16 / 08 / 2020$.

Jung, J. (1990). Global versus health-specific social support and match of preferred and perceived social support levels in relationship to compliance and blood pressure of hypertensives. Journal of Applied Social Psychology, 20(13), 1103-1111. https://doi.org/10.1111/j. 1559-1816.1990.tb00393.x

Kanfer, R., Wanberg, C. R., \& Kantrowitz, T. M. (2001). Job search and employment: A personality-motivational analysis and meta-analytic review. Journal of Applied Psychology, 86(5), 837-855. https://doi. org/10.1037/0021-9010.86.5.837

Lakey, B., \& Cohen, S. (2000). Social support theory and measurement. In S. Cohen, L. G. Underwood, \& B. H. Gottlieb (Eds.), Social support measurement and intervention: A guide for health and social scientists (pp. 29-52). Oxford University Press. https://doi.org/ 10.1093/med:psych/9780195126709.003.0002

Lam, C. M., To, S. M, \& Kwong, W. M. (2020). Development and validation of a questionnaire on Chinese parents' beliefs in parental roles and responsibilities. Applied Research in Quality of Life, 15, 693-712. https://doi.org/10.1007/s11482-018-9682-4

Liss, M., Schiffrin, H. H., Mackintosh, V. H., Miles-Mclean, H., \& Erchull, M. J. (2013). Development and validation of a quantitative measure of intensive parenting attitudes. Journal of Child and Family Studies, 22, 621-636. https://doi.org/10.1007/s10826-012-9616-y

Maier, S. F., \& Seligman, M. E. P. (2016). Learned helplessness at fifty: Insights from neuroscience. Psychological Review, 123(4), 349367. https://doi.org/10.1037/rev0000033

Marbell, K. N., \& Grolnick, W. S. (2013). Correlates of parental control and autonomy support in an interdependent culture: A look at Ghana. Motivation and Emotion, 37(1), 79-92. https://doi.org/10. 1007/s11031-012-9289-2

Markus, H. R., \& Kitayama, S. (1991). Culture and the self: Implications for cognition, emotion, and motivation. Psychological Review, 98, 224-253. https://doi.org/10.1037/0033-295x.98.2.224

Markus, H. R., \& Kitayama, S. (2010). Cultures and selves: A cycle of mutual constitution. Perspectives on Psychological Science, 5(4), 420-430. https://doi.org/10.1177/1745691610375557

Matud, M. P., Ibáñez, I., Bethencourt, J. M., Marrero, R., \& Carballeira, M. (2003). Structural gender differences in perceived social support. Personality and Individual Differences, 35(8), 1919-1929. https:// doi.org/10.1016/S0191-8869(03)00041-2

McKee-Ryan, F. M., Song, Z., Wanberg, C. R., \& Kinicki, A. J. (2005). Psychological and physical well-being during unemployment: A 
meta-analytic study. Journal of Applied Psychology, 90, 53-76. https://doi.org/10.1037/0021-9010.90.1.53

McLarnon, M. J. W., Goffin, R. D., Schneider, T. J., \& Johnston, N. G. (2016). To be or not to be: Exploring the nature of positively and negatively keyed personality items in high-stakes testing. Journal of Personality Assessment, 98(5), 480-490. https://doi.org/10.1080/ 00223891.2016 .1170691

Meredith, W., \& Teresi, J. A. (2006). An essay on measurement and factorial invariance. Medical Care, 44(11 Suppl 3), S69-S77. https://doi.org/10.1097/01.mlr.0000245438.73837.89

Mokona, H., Yohannes, K., \& Ayano, G. (2020). Youth unemployment and mental health: Prevalence and associated factors of depression among unemployed young adults in Gedeo zone, southern Ethiopia. International Journal of Mental Health Systems, 14, 61. https://doi. org/10.1186/s13033-020-00395-2

Molina, J. G., Rodrigo, M. F., Losilla, J.-M., \& Vives, J. (2014). Wording effects and the factor structure of the 12-item general health questionnaire (GHQ-12). Psychological Assessment, 26(3), 1031-1037. https://doi.org/10.1037/a0036472

Mousteri, V., Daly, M., \& Delaney, L. (2018). The scarring effect of unemployment on Psychological well-being across Europe. Social Science Research, 72, 146-169. https://doi.org/10.1016/j. ssresearch.2018.01.007

Ng, S.-M. (2013). Validation of the 10-item Chinese perceived stress scale in elderly service workers: One-factor versus two-factor structure. BMC Psychology, 1, 9 http://www.biomedcentral.com/2050-7283/1/9

Nukunya, G. K. (2016). Tradition and change in Ghana. An introduction to sociology. Woeli Publishing Services.

Osborne, J. W. (2014). Best practices in exploratory factor analysis. CreateSpace Independent Publishing.

Paul, K. I., \& Moser, K. (2009). Unemployment impairs mental health: Meta-analyses. Journal of Vocational Behavior, 74, 264-282. https://doi.org/10.1016/j.jvb.2009.01.001

Pendergast, L. L., von der Embse, N., Kilgus, S. P., \& Eklund, K. R. (2017). Measurement equivalence: A non-technical primer on categorical multi-group confirmatory factor analysis in school psychology. Journal of School Psychology, 60, 65-82. https://doi.org/10. 1016/j.jsp.2016.11.002

Peterson, C. (2010). Learned helplessness. In I. B. Weiner \& W. E. Craighead (Eds.), The Corsini encyclopedia of psychology. John Wiley \& Sons. https://doi.org/10.1002/9780470479216.corpsy0500

Putnick, D. L., \& Bornstein, M. H. (2016). Measurement invariance conventions and reporting: The state of the art and future directions for psychological research. Developmental Review, 41, 71-90. https://doi.org/10.1016/j.dr.2016.06.004

Rife, J. C., \& Belcher, J. R. (1993). Social support and job search intensity among older unemployed workers: Implications for employment counselors. Journal of Employment Counseling, 30(3), 98-107. https://doi.org/10.1002/j.2161-1920.1993.tb00167.x

Roszkowski, M. J., \& Soven, M. (2010). Shifting gears: Consequences of including two negatively worded items in the middle of a positively worded questionnaire. Assessment \& Evaluation in Higher Education, 35(1), 117-134. https://doi.org/10.1080/ 02602930802618344

Salm, S., \& Falola, T. (2002). Culture and customs of Ghana. Greenwood Press.

Sarason, I. G., \& Sarason, B. R. (2009). Social support: Mapping the construct. Journal of Social and Personal Relationships, 26(1), 113-120. https://doi.org/10.1177/0265407509105526

Sarason, I. G., Sarason, B. R., \& Pierce, G. R. (1994). Social support: Global and relationship-based levels of analysis. Journal of Social and Personal Relationships, 11, 295-312. https://doi.org/10.1177/ 0265407594112008

Schwartz, S. H. (2006). A theory of cultural value orientations: Explication and applications. Comparative Sociology, 5, 136-182. https://doi.org/10.1163/156913306778667357
Smallheer, B. A., \& Vollman, \& Dietrich, M. S. (2018). Learned helplessness and depressive symptoms following myocardial infarction. Clinical Nursing Research, 27(5), 597-616. https://doi.org/10.1177/ 1054773816689752

The Inglehart-Welzel World Cultural Map. (2020). World Values Survey 7 [provisional version]. http://www.worldvaluessurvey.org/

Thern, E., de Munter, J., Hemmingsson, T., \& Rasmussen, F. (2017). Long-term effects of youth unemployment on mental health: Does an economic crisis make a difference? Journal of Epidemiology and Community Health, 71, 344-349. https://doi.org/10.1136/jech2016-208012

Uchino, B. N. (2006). Social support and health: A review of physiological processes potentially underlying links to disease outcomes. Journal of Behavioral Medicine, 29(4), 377-387. https://doi.org/ 10.1007/s10865-006-9056-5

Uz, I. (2015). The index of cultural tightness and looseness among 68 countries. Journal of Cross-Cultural Psychology, 46(3), 319-335. https://doi.org/10.1177/0022022114563611

Van Sonderen, E., Sanderman, R., \& Coyne, J. C. (2013). Ineffectiveness of reverse wording of questionnaire items: Let's learn from cows in the rain. PLoS One, 8(7), e68967. https://doi.org/10.1371/journal. pone. 0068967

Vandenberg, R. J. (2002). Toward a further understanding of an improvement in measurement invariance methods and procedures. Organizational Research Methods, 5(2), 139-158. https://doi.org/ $10.1177 / 1094428102005002001$

Vandenberg, R. J., \& Lance, C. E. (2000). A review and synthesis of the measurement invariance literature: Suggestions, practices, and recommendations for organizational research. Organizational Research Methods, 3(1), 4-69. https://doi.org/10.1177/ 109442810031002

Vansteenkiste, S., Verbruggen, M., \& Sels, L. (2016). Flexible job search behavior among unemployed job seekers: Antecedents and outcomes. European Journal of Work and Organizational Psychology, 25(6), 862-882. https://doi.org/10.1080/1359432X. 2016.1168402

Vinokur, A. D., \& van Ryn, M. (1993). Social support and undermining in close relationships: Their independent effects on the mental health of unemployed persons. Journal of Personality and Social Psychology, 65, 350-359. https://doi.org/10.1037//0022-3514.65.2.350

West, S. G., Taylor, A. B., \& Wu, W. (2012). Model fit and model selection in structural equation modeling. In R. H. Hoyle (Ed.), Handbook of Structural Equation Modeling (pp. 209-231). The Guilford Press.

World Bank. (2020). Addressing youth unemployment in Ghana needs urgent action, calls new World Bank Report. Retrieved from https:// www.worldbank.org/en/news/press-release/2020/09/29/addressingyouth-unemployment-in-ghana-needs-urgent-action. Accessed 23 Jan 2021

Yeboah, O. A. (2019). How unemployment is 'stealing' the youths' future. Retrieved from https://thebftonline.com/2019/economy/howunemployment-is-stealing-the-youths-future/, accessed on 16/08/ 2020.

Zhou, M. (2019). Gender differences in the provision of job-search help. Gender \& Society, 33(5), 746-771. https://doi.org/10.1177/ 0891243219854436

Zimet, G. D., Dahlem, N. W., Zimet, S. G., \& Farley, G. K. (1988). The multidimensional scale of perceived social support. Journal of Personality Assessment, 52(1), 30-41. https://doi.org/10.1207/ s15327752jpa5201_2

Publisher's Note Springer Nature remains neutral with regard to jurisdictional claims in published maps and institutional affiliations. 